\title{
Management of Mild Aortic Stenosis in Patients Undergoing Coronary Bypass Surgery
}

\author{
Fábio Cañellas Moreira, Waldomiro C. Manfroi, Gustavo Werutsky, José Augusto Ferreira Bittencourt \\ Porto Alegre, RS - Brazil
}

Many patients with coronary artery disease who require myocardial revascularization have asymptomatic mild aortic stenosis. Mild valvular obstruction is defined as a valvular area greater than $1.5 \mathrm{~cm}^{2}$, maximum transvalvar gradient less than $30 \mathrm{mmHg}$, and maximum flow velocity lower than $3 \mathrm{~m} / \mathrm{s}$. Even though the management of patients with obstructive aortic valvular disease has already been defined for most situations, and basically depends on symptoms, the approach with these patients remains controversial as noted in the literature. Aortic valvular replacement occurring simultaneously with myocardial revascularization surgery is considered a class IIb indication according to the guidelines elaborated by the committee on management of patients with valvular disease of the American College of Cardiology/American Heart Association ${ }^{1}$. Some authors have recommended valvular replacement simultaneously with revascularization, reasoning that progression of the aortic stenosis to a critical stage takes approximately 5 to 8 years. Therefore, a significant percentage of these patients undergo early reintervention caused only by the valvular disease, being exposed to an increased risk mainly due to age, even with previous bypasses ${ }^{2}$. Other factors associated with higher risk could be the following: the possible need for redissection of the internal mammary artery, the possible embolization of calcium in the damaged saphenous veins, and suboptimal myocardial protection caused by left ventricular hypertrophy.

However, other groups have argued that the simultaneous procedure in a patient with mild asymptomatic stenosis imposes morbidity and mortality related to the use of prostheses. This reasoning is supported by the evidence that, in an 8-year interval (period of valvular disease evolution), mechanical valves account for $30 \%$ of this morbidity and mortality, and biological valves for $15 \%$ to $20 \%{ }^{3}$. In

Universidade Federal do Rio Grande do Sul - Porto Alegre

Mailing address: Fábio Cañellas Moreira - Av. Mariland, 1372/202 - 90440-190

- Porto Alegre, RS, Brazil - E-mail: fabiocm@cardiol.br

English version by Stela Maris C. e Gandour addition, mortality rates as high as $18 \%$ have been reported for the isolated procedure ${ }^{4}$.

In 1988, Horstkotte et $\mathrm{al}^{5}$, assessing 142 patients with mild aortic stenosis, valvular area greater than $1.5 \mathrm{~cm}^{2}$, and undergoing catheterization because of other causes, found a 10 -year survival of $92 \%$, with a $22 \%$ evolution to critical aortic stenosis in 20 years and $38 \%$ in 25 years. In addition, $88 \%$ of the patients remained with mild obstruction after 10 years and $63 \%$ after 20 years.

Recently, Otto et al ${ }^{6}$ reported the evolution of aortic valvular disease and showed that an increase of $0.32 \mathrm{~m} / \mathrm{s} /$ year exists in the velocity of transvalvar flow, with an increase in the mean gradient of approximately 3.9 to $7 \mathrm{mmHg} /$ year, and a reduction in the valvular area of $0.12 \mathrm{~cm}^{2}$ per year.

Collins et $\mathrm{al}^{7}$, retrospectively assessing a group of 44 previously revascularized patients undergoing reoperation because of symptomatic aortic stenosis, reported symptoms in $75 \%$ of the patients in a 5-year period, with a mean evolution of 68 months, even though some cases evolved in 8 months (evolution ranging from 8 to 164 months).

Several attempts were made to find adequate and more reliable markers of progression of aortic stenosis. Davies et al ${ }^{8}$ showed that the progression rate was not related to age, sex, or initial gradient, but to the valvular anatomy and the degree of calcification, rheumatic valvular disease being accompanied by less calcification and a lower progression rate. Wagner and Selker ${ }^{9}$ showed that the valvular fibrotic degeneration with calcification was associated with more rapid progression and greater degrees of calcification, unlike the congenital valvular disease, bicuspid valve, which remained in an intermediate position. However, Fiore et $\mathrm{al}^{3}$ showed more rapid progression in congenital valvular disease as compared with rheumatic disease, and this fact was supported by Hoshtkotte et al ${ }^{5}$.

In 1988, Lytle et al ${ }^{10}$, in a retrospective study with a cohort of 294 patients undergoing myocardial revascularization surgery and aortic valvular replacement, simultaneously, found an in-hospital mortality of $4.4 \%$ with a 2-year survival of $89 \%$ and a 10 -year survival of $52 \%$. Another group of patients was reviewed in the following decade, and 
a slightly higher mortality was observed (5.3\%). These values were similar to the mortality rates of the isolated surgical procedures of myocardial revascularization.

Stahle et al ${ }^{11}$, in the same way, showed a slight increase in mortality with the association of procedures. They compared retrospectively 659 patients undergoing myocardial revascularization alone with 303 patients undergoing aortic valvular replacement and myocardial revascularization simultaneously, and they found a 30-day mortality of $4.6 \%$ and $5.9 \%$ in the $1^{\text {st }}$ and $2^{\text {nd }}$ groups, respectively. Likewise, Herlitz et al ${ }^{12}$ showed that the simultaneous procedures were not associated with higher mortality and readmission rates in a 5-year follow-up.

Between 1975 and 1992, 42 patients who had previously undergone myocardial revascularization were reoperated upon for aortic valvular replacement in the Brigham and Women's Hospital. Most patients (95\%) had fibrotic degeneration and calcification. In this group, mortality was $23.5 \%$, far higher than that reported for patients undergoing the simultaneous procedures in the same period $(6.6 \%)$ and the myocardial revascularization alone $(3.3 \%)^{7}$.

Fighali et al ${ }^{13}$, analyzing 104 patients who had previously undergone myocardial revascularization and were indicated for aortic valvular replacement due to valvar stenosis (68\%), reported increased early and late (35 months) mortalities (14\% and 17\%, respectively). They stressed that $70 \%$ of these patients had congestive heart failure and most of them had multivessel disease. Despite this, survivals in 1 year and 5 years were $95 \%$ and $75 \%$, respectively.

In a similar manner, Fiore et $\mathrm{al}^{3}$ studied 28 patients undergoing aortic valvular replacement within $8 \pm 4$ years after myocardial revascularization in the period from 1980 to 1994. They showed that, when compared with patients undergoing the simultaneous procedures (175 patients), their patients had higher early mortality; however, this difference did not persist by the end of 10 years. Nevertheless, $75 \%$ of the reoperated upon patients required another revascularization procedure. Postoperative complications, such as renal failure (11\% vs $1.1 \%)$, low cardiac output ( $29 \%$ vs $8.7 \%$ ), and ventricular arrhythmias (50\% vs $13 \%$ ) were significantly more frequent in the reoperated upon group.

On the other hand, Sundt et $\mathrm{al}^{4}$, in a retrospective study of 11.5 years (1985-1996), showed no difference in morbidity and mortality in 30 days between the group receiving aortic valvular replacement and that receiving postoperative reoperation of myocardial revascularization (total mortality of $6.6 \%$ vs $7.7 \%$ ). In the multivariate analysis, reoperation was not a predictor of mortality in the postoperative period.

More recently, Tam et al ${ }^{14}$ analyzed retrospectively some patients with symptomatic arterial disease, dividing them into 2 groups as follows: group A - those with mild aortic stenosis undergoing myocardial revascularization surgery alone; and group B - those undergoing the simultaneous procedures. Patients in group $B$ had a higher score of valvular calcification and lower degrees of mobility of the valvular leaflets, even though the gradients were not statistically different in the 2 groups. In 48 months, a favorable tendency occurred in group A in regard to event-free survival, but this tendency did not persist when age adjustments were performed (0.10). In group A, 19 events (11 deaths and 8 aortic valvular replacements) occurred, but no patient requiring valvular replacement died. In group B, 8 events ( 5 deaths and 3 complications of the prosthesis) occurred. Out of the 28 event-free patients, 22 underwent echocardiography, which showed an instantaneous maximum gradient of $40 \pm 23 \mathrm{mmHg}$ and valvular area of $1.3 \pm 0.7 \mathrm{~cm}^{2}$ in a mean follow-up of $67 \pm 47$ months. In a multivariate analysis, the only predictors of stenosis progression were the initial gradient $(20.7 \pm 9.9 \mathrm{mmHg}$ vs $9.6 \pm 7.1 \mathrm{mmHg}$; $\mathrm{p}=0.0005)$ and calcium score ( $1.3 \pm 0.7$ vs $0.8 \pm 0.7 ; \mathrm{p}=0.06$ ). The impact of the gradient was even more deeply analyzed when group A was subdivided into 2 subgroups based on the mean gradient (above or below $12 \mathrm{mmHg}$ ). Patients with an aortic gradient above $12 \mathrm{mmHg}$ had a poorer outcome with an odds ratio of 3.74 adjusted for age $(95 \% \mathrm{CI}=1.16$ 11.96; $p=0.02$ ). In this study, however, the cause of the aortic valvular disease was not considered.

In another series ${ }^{15}$ prospectively followed up since 1994 and comprising 128 patients with asymptomatic severe aortic stenosis (velocity $=5 \pm 0.6 \mathrm{~m} / \mathrm{s}$ ), only the extension of the calcification was an independent predictor of cardiovascular events (valvular replacement or death) in multivariate analysis. In addition, in a follow-up of $22 \pm 18$ months, 67 outcomes were observed ( 8 deaths and 59 valvular replacements), event-free survival being $67 \pm 5 \%$ in 1 year, $56 \pm 5 \%$ in 2 years, and $33 \pm 5 \%$ in 4 years. Even though comprising patients with characteristics different from those of our review, this study emphasizes the importance of assessing the degree of valvular calcification through echocardiography in regard to deciding about simultaneous valvular replacement.

Despite all that, Hochrein et al ${ }^{16}$ of the Department of Medicine and Surgery of Duke University recommended in a recent publication simultaneous valvular replacement. Even though no difference existed in total mortality in 30 days $(9.8 \%$ myocardial revascularization surgery vs $11.2 \%$ aortic valvular replacement and myocardial revascularization surgery) and in total and cardiac mortality, when the patients followed up for more than 6 years were compared through the Cox proportional hazards model, the estimated need for reoperation was $24.3 \%$ in the group of myocardial revascularization surgery alone and $3.0 \%$ in the group of the associated procedures $(\mathrm{p}=0.002)$.

Conclusion - Contrary to that which happens with ischemic heart disease, the current management of aortic stenosis is based on symptoms, even if the valvular disease is severe.

However, in individuals with asymptomatic valvular disease who will undergo myocardial revascularization surgery, the management does not depend on symptoms. As emphasized in the guidelines, patients with significant stenosis should undoubtedly undergo associated proce- 
dures (evidence grade I ). In the patients with transvalvar flow velocity ranging from 3 to $4 \mathrm{~m} / \mathrm{s}$ (gradient ranging from 36 to $64 \mathrm{mmHg}$ ), the decision should be individualized (Grade IIB). This is due to the fact that $40 \%$ of these patients require valvular replacement within 2 years, and almost $80 \%$ in 5 years, therefore, blurring any benefit provided by myocardial revascularization surgery.

On the other hand, for patients with gradients less than $36 \mathrm{mmHg}$ or velocity $<3 \mathrm{~m} / \mathrm{s}$, the indication is still more controversial (Grade IIB), because the natural history of mild stenosis varies; some patients rapidly evolve towards a reduction in the valvular area of $0.3 \mathrm{~cm}^{2} / y e a r$ and a gradient increase of $15-19 \mathrm{mmHg} /$ year $^{1}$.

Therefore, despite the great advances in surgical techniques, mainly in the area of myocardial protection and preservation, during surgery, the risk of a prophylactic valvular replacement needs to be weighed against the risks of the potential worsening of the valvular disease and the increase in morbidity and mortality associated with the new intervention at a more advanced age ${ }^{17}$.

Some findings, such as the initial gradient $(>20-$ $25 \mathrm{mmHg}$ ), the calcification degree, valvular mobility, and the degenerative etiology, even though derived from retrospective studies, may suggest that we are facing a valve that may evolve to stenosis more rapidly, and this may void all benefits caused by myocardial revascularization surgery.

In the case of valvular replacement simultaneously with myocardial revascularization surgery, we may perhaps be exchanging a possible future disease for a defined morbidity associated with the use of prostheses. Therefore, to clarify this subject and better support our decision, results of randomized prospective studies are required.

\section{References}

1. Guidelines for the management of patients with valvular heart disease. Executive summary. A Report of the American College of Cardiology/American Heart Association Task Force on Practice Guidelines (Committee on Management of Patients with Valvular Heart Disease. Circulation 1998; 98: 1949-84.

2. Wong PS, Davies SW, Youhana A, Wright JE, Magee PG. Coronary artery bypass surgery and minor aortic stenosis - to replace or not to replace? J Heart Valve Dis 1993; 2: 649-52.

3. Fiore AC, Swartz MT, Swart BA, et al. Management of asymptomatic mild aortic stenosis during coronary artery operations. Ann Thorac Surg 1996; 61: 1683-8.

4. Sundt III TM, Murphy SF, Barzilai B, et al. Previous coronary artery bypass grafting is not a risk factor for aortic valve replacement. Ann Thorac Surg 1997; 64: 651-8.

5. Horstkotte D, Loogen F. The natural history of aortic valve stenosis. Eur Heart J 1988; 9(suppl E): 57-64.

6. Otto Catherine M. Aortic Stenosis: Echocardiographic Evaluation of Disease Severity, Disease Progression, and the Role of Echocardiography in Clinical Decision Making. In: The Practice of Clinical Cardiology.: WB Saunders Co., 1997: 406-32.

7. Collins JJ, Aranki SF. Management of mild aortic stenosis during coronary artery bypass graft surgery. J Card Surg 1994; 9(suppl): 145-7.

8. Davies SW, Gershlick AH, Baloon R. Progression of valvar aortic stenosis: a long-term retrospective study. Eur Heart J 1991; 12: 10-4.

9. Wagner S, Selker A. Patterns of progression of aortic stenosis: a longitudinal hemodynamic study. Circulation 1982; 65: 709-12.
10. Lytle BW, Cosgrove DM, goormastic M, Loop FD. Aortic valve replacement and coronary bypass graft for patients with aortic stenosis and coronary artery disease: early and late results. Eur Heart J 1988; 9(suppl E): 143-7.

11. Stahle E, Bergstrom R, Nystrom SO, Hansson HE. Early results of aortic valve replacement with or without concomitant coronary artery bypass grafting. Scand J Thorac Cardiovasc Surg 1991; 25: 29-35.

12. Herlitz J, Brandrup-wognsen G, Caidahl K, et al. Mortality among patients who undergo combined valve and coronaryartery bypass surgery: early and late results. Eur J Cardiothorac Surg 1997; 12: 836-46.

13. Fighali SF, Avendano A, Elayda MA, et al. Early and late mortality of patients undergoing aortic valve replacement after previous coronary artery bypass graft surgery. Circulation 1995; 92(suppl 9): II 163-8.

14. Tam JW, Masters RG, Burwash IG, Mayhew AD, Chan KL. Management of patients with mild aortic stenosis undergoing coronary artery bypass grafting. Ann Thoracic Surg 1998; 65: 1215-9.

15. Rosenhek R, Binder T, Porenta G, et al. Predictors of outcome in severe, asymptomatic aortic stenosis. N Engl J Med 2000; 343-9: 611-7.

16. Hochrein J, Lucke JC, Harrison JK, et al. Mortality and need for reoperation in patients with mild to moderate asymptomatic aortic valve disease undergoing coronary artery bypass graft alone. Am Heart J 1999; 138: 791-7.

17. Hilton TC. Aortic valve replacement for patients with mild to moderate aortic stenosis undergoing coronary artery bypass surgery. Clin Cardiol 2000; $23: 141-7$. 